\title{
Vertical Foreclosure with the Choice of Input Specifications
}

by

Jay Pil Choi, Columbia University

Sang-Seung Yi, Dartmouth College

July 1996, rev. January 1997

Discussion Paper Series No. 9697-11

$d p 9697-11$

pages: 44 


\title{
Vertical Foreclosure with the Choice of Input Specifications
}

by

Jay Pil Choi* and Sang-Seung $\mathrm{Yi}^{* *}$

July 1996

revised, January 1997

\begin{abstract}
This paper develops an equilibrium model of vertical foreclosure with the choice of input specifications. In this model, vertical foreclosure occurs as the upstream division of the integrated firm makes a specialized input for its sister downstream division while it would, as an independent firm, provide a generalized input. The changes in incentives with vertical integration can be explained by the externalities the choice of a specialized input entails; vertical integration allows the upstream firm to internalize the benefit of rajsing the rival firm's costs at the downstream level. The choice of a specialized input by the integrated firm serves as a natural commitment mechanism not to supply the rival downstream firms, and thus enables us to dispense with the controversial price commitment assumption in the literature. We derive conditions for equilibrium vertical foreclosure to occur and discuss its welfare consequences.

\footnotetext{
*Department of Economics, Columbia University

**Department of Economics, Dartmouth College
}

We are grateful to Kyle Bagwell, Yeon-Koo Che, Chaim Fershtman, Joseph Harrington, Paul Klemperer, and John McLaren for useful discussions. The preliminary version of this paper was prepared while the first author was visiting the CentER, the Netherlands, whose hospitality and excellent research support are gratefully acknowledged.
\end{abstract}




\section{Introduction}

Anti-competitive effects of vertical mergers continue to be a source of disagreement among economists and antitrust practitioners. This lack of consensus, reflected by large pendulous swings over time in the antitrust enforcement activities regarding vertical mergers, is mainly due to the fact that the intellectual foundation of the classical foreclosure theory was laid on shaky ground. Legal commentators, in particular, from the Chicago school revealed the logical flaws and ill-conceivedness of the theory and subsequently argued that vertical integration was most likely to be pro-competitive or competitively neutral (Bork, 1978). Their criticisms had a major influence on antitrust activities and was largely responsible in the 1970's and 1980's for the dormancy of antitrust enforcement with vertical elements (Riordan, 1995). ${ }^{1}$

The Chicago school criticism, however, has also spawned a new research program that attempts to place vertical foreclosure theory on a firmer theoretical ground with game-theoretic foundations (see Ordover, Salop, and Saloner [1990]; Hart and Tirole [1990]; Bolton and Whinston [1993]; and Salinger [1988]). Ordover, Salop, and Saloner (henceforth, O-S-S), for instance, construct an equilibrium model of vertical foreclosure that purportedly answers all the major elements of the Chicago school criticism, such as the possibility of a counter-merger by the foreclosed firm and the hold-out incentives that the target upstream firm may have in the acquisition process. As pointed out by Reiffen (1992) and many others, however, O-S-S's model is deficient in making the assumption that the vertically integrated firm is able to make a price commitment to the nonintegrated downstream firm. ${ }^{2}$ This assumption essentially transforms the vertically integrated firm into a Stackelberg leader and changes the nature of the input pricing game (see Reiffen's

\footnotetext{
'The pace of government enforcement activities, however, picked up recently especially in telecommunications industry (Klass and Salinger, 1995)

${ }^{2}$ Reiffen and Vita (1995) state that "the Ordover et al. analysis leaves unanswered the question that dogged earlier efforts to provide an economic rationale for a relationship between integration and foreclosure...Ordover et al.'s ability to obtain a post-merger price increases is an artifact of an inconsistency in their model."
} 
[1992] comment and Ordover, Salop, and Saloner's [1992] reply for details).

In this paper, we develop a model of vertical foreclosure which dispenses with the controversial assumption of price commitment in the O-S-S model; the integrated firm is allowed to undercut the rival upstream firm whenever it is profitable. In other aspects, we closely follows O-S-S in that the model fully accounts for the availability of a conterstrategy by the foreclosed firm and the possibility of a hold-out problem by the target firm in the vertical merger process. ${ }^{3}$

Consider a situation in which downstream firms produce differentiated products. As a result of producing differentiated output, it is assumed that they demand differentiated inputs from upstream firms. This may be due to the fact that they employ different manufacturing processes or that differentiated outputs simply require a different specification of inputs. Our formulation departs from O-S-S and the existing literature in that the upstream firms make decisions with respect to the specification of the input demanded by the downstream firms. In particular, we assume that the upstream firms can choose (only) one of the following with respect to input specifications: a generalized input that can be used by both downstream firms or a specialized input that is dedicated to one of the two downstream firms. We further assume that the input specialized for one of the downstream firms is less useful to the other downstream firm. Therefore, an upstream firm's decision to supply one of the specialized inputs can serve as a commitment mechanism to foreclose (downstream) firms other than the one the input is specifically designed for. By introducing differentiated inputs, our formulation thus provides a natural setting where the issue of vertical foreclosure can be addressed.

With this framework, we demonstrate that under the non-integrated vertical

\footnotetext{
${ }^{3}$ The reason for considering these possibilities is to meet the objections of the "Chicago School" who argue that vertical foreclosure is implausible as an equilibrium phenomenon when these possibilities are explicitly taken into account. See the discussion in O-S-S (1990) for more details. Aghion and Bolton (1987), Rasmusen, Ramseyer, and Wiley (1991), and McAfee and Schwartz (1994) also emphasize the need to consider a fully specified equilibrium model for a meaningful analysis of the rationality and the welfare implications of exclusionary strategies.
} 
structure, both upstream firms tend to choose the generalized input and compete for the businesses of both downstream firms. However, (partial) vertical integration changes the integrated upstream firm's incentives concerning input specification; the integrated upstream firm switches its input specification from the generalized input to the specialized input for the downstream firm that belongs to the same integrated structure. The main intuition for this result can be explained by considering the external effects associated with the choice of a specific input. When one upstream firm, say U1, chooses a specialized input for one of the downstream firms, D1, U1 raises the cost of the other downstream firm D2 because of its withdrawal as D2's potential supplier. As a result, D1 benefits from Ul's decision to tailor its input supply for D1. This beneficial effect is not accounted for when U1 makes its input specification decision as an independent firm. Since the choice of a specialized input entails giving up the chance to supply the rest of the market, no upstream firm is willing to supply specialized inputs when they operate as an independent firm. After integration, however, if the beneficial effect of raising the rival firm's costs is sufficiently large, then the integrated firm may decide to supply the specialized input even if it must forego the chance to profitably supply the other downstream firm.

Why then will the nonintegrated downstream firm whose costs have been raised, not react with a counter-merger of its own to mitigate the adverse effect of its rival's initial merger? The crucial link in our model is provided by the stochastic nature of cost realizations. We assume that input costs are more positively correlated when the same type of input is produced. For a variety of oligopoly models, competition is more intense when firms are more symmetrically positioned in terms of costs. Therefore, firms are collectively better off when their cost structure is asymmetric across firms (see Tirole, 1988, p. 223). This implies that the reduction of cost correlation via the choice of a specialized input is similar to the provision of a public good; the cost of choosing a specialized input is the foregone chance to serve the other half of the market, and it is 
borne out by the individual firm while the benefit of reduced cost correlation accrues to both upstream firms. Thus, from the collective viewpoint of the upstream firms, their costs tend to be too correlated in the market outcome due to the undersupply of the public good, that is, they choose the same specification of input (the generalized input) too often. ${ }^{4}$ Partial vertical integration enhances the private benefit of providing the public good (i.e., choosing a specialized input) by internalizing the beneficial effect of raising the rival firm's costs at the downstream level. This effect induces the integrated firm to undertake the provision of the public good itself and to overcome the public good problem. It will, however, be shown that under wide circumstances, a counter-merger changes the incentive of the initially integrated firm to revert back to the choice of the generalized input. The reason is that the rival downstream firm will now be supplied at the marginal cost of input production with the merger of its own and the effect of raising the rival firm's costs, which was responsible for the choice of a specialized input by the integrated firm under partial integration, no longer exists. As a result, a counter-merger can strip the initially merged firm of the incentive to provide the public good (reduced cost correlation) and can intensify competition. This threat prevents counter-mergers from being materialized.

Our paper closely relates to McLaren (1996) who considers the incentive for vertical integration that arises from the possibility of post-contractual opportunistic behavior with specialized assets (Klein, Crawford, and Alchian, 1978). As in our paper, his model allows for the endogenous choice of the degree of asset specificity by input providers. Vertical integration in his model creates a negative externality for outsiders by "thinning" the market for inputs and, thus, worsening opportunism problems. As he concedes in his own paper, however, he is not concerned with the "foreclosure" motive of

\footnotetext{
${ }^{4}$ This result is reminiscent of Dasgupta and Maskin (1987) who show that the market portfolio of R\&D projects is characterized by excessive correlation due to a similar reason. As a firm moves away from its rival in the space of research projects, it bestows a positive externality on the rival firm in that the likelihood that the rival is successful when the firm in question is not, increases. This externality is not take into account in the private firms' $R \& D$ portfolio decisions.
} 
vertical integration, which is the main concern of our paper. Rather, his focus is on how international trade affects the vertical structure of an industry by "thickening" the market. McLaren shows that greater international openness brings convergence in the degree of outsourcing across countries and promotes a less integrated vertical structure. In addition, vertical integration in McLaren's model possesses the property of "strategic complementarity" which can lead to multiple equilibria in the integration decisions.

Therefore, the vertical integration of one pair of upstream and downstream firms sets off a chain reaction involving the other firms. In contrast, we are interested in the case where a counter-merger is unprofitable and the effects of a foreclosure persist.

Our model also relates to Church and Gandal (1995), who consider the possibility of foreclosure in systems markets where a final good consists of a hardware good and complementary software. They consider two options for software firms in their format decisions: Software firms can elect to either to make the software available only in a format compatible with one particular hardware system or in formats compatible with both systems. In their model, foreclosure takes place when the integrated firm refuses to supply compatible software for a rival system because the value of a system depends on the availability of software compatible with the system. Thus, the two options for software firms in Church and Gandal (1995) correspond to the choice of a specialized input and a generalized input in our model, respectively. ${ }^{5}$ In this respect, the model of Church and Gandal can be considered as a special case of ours if the format decision in their model is assumed to be an irreversible decision. ${ }^{6}$ In Church and Gandal, however, there are no

\footnotetext{
${ }^{5}$ Church and Gandal (1995) also follow the lead of O-S-S in that they consider a fully specified multistage game where the possibilities of a counter strategy and a bold-out problem are accounted for. ${ }^{6}$ Church and Gandal (1995) assume a timing structure in which consumers purchase hardware first, then software to avoid the possibility that software vendors affect the market share of a hardware technology by their pricing decisions. As a result, only the number of software varieties compatible with each hardware system will determine the market share. They argue that their results are robust to changes in the timing of the compatibility decision in that the same results are derived if an integrated firm simultaneously chose its hardware price and its software format. However, if the integrated firm is given a chance to introduce its software in a format compatible with the rival firm's system after consumers purchase hardware, it will have an ex past incentive to do so. Therefore, their model suffers from the same type of
} 
offsetting efficiencies associated with vertical merger and foreclosure because the relationship between the hardware and software firms are not purely vertical in their model. In addition, their timing assumption on the order of consumers' purchases (hardware first and then software) deprives the integrated firm of the possibility to eliminate any markup in the software market. In contrast, our model allows for the possibility of successive markups when firms are not vertically integrated, one of the central issues in the vertical integration literature (Spengler, 1950). Thus, we are able to assess the conditions under which the harmful effects from vertical mergers outweigh the beneficial ones (Klass and Salinger, 1995).

It is interesting to note that our model seemingly generates the same type of postintegration behavior as in Porter and Spence (1977). They develop a model of vertical integration in which a downstream firm is prompted to integrate backwards due to its inability to obtain on the market inputs with a desired set of attributes. One implication of their model, therefore, is that the vertically integrated upstream firm will produce inputs with specifications tailored for its sister downstream firm, inputs that were not offered before on the market. Despite this similarity in the post-integration behavior, the motivations behind vertical integration are quite different across models. In Porter and Spence, the procurement of a specialized input tailored for its downstream division is the end itself. If any harmful effect on welfare stems from vertical integration, it is an unintended side effect. In our model, the choice of a specialized input is used as a means of foreclosure for the purpose of raising the rival firm's costs (Salop and Scheffman, 1983) and therefore, its purpose is more vicious than Porter and Spence (1977). Finally, in a model of vertical integration with supply assurance motives, Carlton

commitment problem unless the compatibility decision is an irreversible decision that is made before or with the hardware pricing decision.

${ }^{7}$ O-S-S (1990) and Hant and Tirole (1990) also abstract from the issue of doubel marginalization in their analyses. O-S-S assumes Bertrand competition upstream with a homogeneous input and identical marginal costs under the unitegrated vertical structure. Hart and Tirole allows for perfect two-part tariffs to eliminate successive markups. 
(1979) assumes that an integrated firm cannot sell its inputs on the open market but does not explain why. Our model, in a sense, supplies a theoretical foundation for Carlton's assumption.

The remainder of the paper is organized in the following way. Section II develops an equilibrium model of vertical foreclosure with the choice of input specifications. We derive conditions for vertical foreclosure to occur and discuss its welfare consequences. In section III, we analyze an example of a Hotelling-type spatial competition. The consideration of an explicit example allows us to completely characterize the region where welfare-reducing vertical foreclosure occurs. Concluding remarks follow.

\section{The Moded}

\section{A. Set-up}

We consider two downstream firms, D1 and D2, which compete in the final goods market. Two upstream firms, $\mathrm{U} 1$ and $\mathrm{U} 2$, supply inputs to the two downstream firms. Upstream firms engage in price competition for the business of downstream firms. Downstream firms transform one unit of the intermediate good into one unit of the final good, and are assumed to incur no costs other than the input prices they pay to the upstream suppliers. At this stage, we do not make any assumptions about the nature of competition in the final goods market - D1 and D2 could play either a pricing or an output game. Instead, we will just write the equilibrium outputs and profits for each downstream firm as reduced-form functions of the vector of constant marginal costs (input prices they pay to the upstream firms). We assume that demand functions are symmetric and therefore, profit functions are also symmetric across the two downstream firms. This symmetry assumption enables us to write the equilibrium output and profit for a

representative downstream firm simply as $q(x, y)$ and $\pi(x, y)$, where the first component of the arguments $(x)$ refers to its own marginal cost and the second component $(y)$ refers to the rival firm's marginal cost. 
Assumption 1.

$$
\frac{\partial \pi(x, y)}{\partial x}<0, \frac{\partial \pi(x, y)}{\partial y}>0, \frac{\partial q(x, y)}{\partial x}<0 \text {, and } \frac{\partial q(x, y)}{\partial y}>0
$$

Assumption 1 says that a firm's output expands and profit increases as the rival firm's cost increases whereas its output contracts and profit decreases as its own cost increases. This assumption is standard and is satisfied by virtually all oligopoly models with suitable stability conditions.

We depart from O-S-S by allowing the upstream firms to make decisions concerning the specification of the input demanded by the downstream firms. More precisely, we assume that the upstream firms have three alternatives: providing either a generalized input that can be used by both downstream firms (denoted by $G$ ) or a specialized input that is dedicated to one of the two downstream firms $\left(S_{1}\right.$ or $\left.S_{2}\right)$. For simplicity, we assume that a specialized input $S_{1}$ is specifically designed for D1's particular manufacturing process to the extent that it cannot be used economically for the other downstream firm D2, and vice versa. Choosing a specialized input for one particular downstream firm is, therefore, effectively a commitment not to supply the other downstream firm. For instance, a software developer may write a program to fit the peculiarities of a single firm's business, or may design it for the mass market as packaged software (McLaren, 1996). ${ }^{8}$ Another example of specification choice involves IBM in the 1970's which redesigned its mainframe computer interfaces to make it difficult for nonIBM hard drives to be used with them (Brock, 1989).

As it will be made clear below, it is never optimal for both upstream firms to choose the same type of specialized input. In conjunction with the symmetry assumption, this allows us to assume, without loss of generality, that $U 1$ chooses $S_{1}$ and $U 2$ chooses $S_{2}$ if they decide to supply specialized inputs. There are four possible cases of input

\footnotetext{
Japanese software houses are known to fit the former category, developing proprietary systems for particular customers (Babe, Takai, and Mizuta, 1995).
} 
specifications to consider: $(G, G),\left(S_{1}, S_{2}\right),\left(G, S_{2}\right)$ and $\left(S_{1}, G\right)$, where the first and second components in parentheses denote the choices of input specifications by $\mathrm{U} 1$ and $\mathrm{U} 2$, respectively. If $(G, G)$ is the choice made by $U 1$ and $U 2$, both upstream firms are capable of supplying both downstream firms. However, if $\left(S_{1}, S_{2}\right)$ is chosen, the input market for the two downstream firms is effectively segmented since U1 can supply only to D1 and similarly for U2 and D2. As a result, both upstream firms are monopolists in their own segmented markets (only constrained by the competitive fringe as explained below). If (G, $S_{2}$ ) is chosen, D1 can be served only by $U 1$ (and the competitive fringe) because U2 has dedicated its production process to supply for D2 only. However, there is competition between $\mathrm{U} 1$ and $\mathrm{U} 2$ to supply to $\mathrm{D} 2$ because $\mathrm{D} 2$ can use inputs from either upstream firm, the generalized input from $U 1$ or the specialized input from U2. It is worthwhile to note that one consequence of Ui's decision to supply input $S_{i}$ is to limit competition in $\mathrm{Dj}$ 's input market and thus raise Dj's costs, where $i=1,2$ and $i \neq j$.

After the choice of input specificity, the production costs of inputs are realized randomly. To simplify the analysis, we assume that the cost of production takes only two values, $\underline{c}$ and $\bar{c}$, where $\underline{c}<\bar{c}$. The cost uncertainty implies that double marginalization can arise when the firms are not vertically integrated (Spengler, 1950), and thus allows us to assess the conditions under which the harmful effects from vertical mergers outweigh the beneficial ones (Klass and Salinger, 1995). Let the unconditional probability of each cost realization be equal regardless of the choice of input specification, i.e., $\operatorname{Pr}(\underline{c})=\operatorname{Pr}(\bar{c})$ $=1 / 2{ }^{9}$

We allow the possibility of cost correlation across firms. More specifically, we assume that the costs are positively correlated if both firms choose the same input specification. Cost correlation, however, can be reduced if the two upstream firms produce inputs of different specifications. In other words, they are more likely to be

\footnotetext{
${ }^{9}$ We can easily generalize the distributional assumptions without affecting the main qualitative results.
} 
subjected to the same type of common cost shocks if they produce the same input. ${ }^{10}$ For simplicity, we assume that cost realization is independently distributed across firms when inputs are of different specifications. " The only relevant case of correlated production cost, therefore, is when both upstream firms decide to supply the generalized input $(G)$ because producing the same type of specialized input is never optimal for upstream firms.

There are four possible outcomes of cost realizations: $(\bar{c}, \bar{c})(\bar{c}, \underline{c}),(\underline{c}, \bar{c})$, and $(\underline{c}, \underline{c})$. Let $\rho$ be the correlation coefficient between the costs of two upstream firms when both choose $G$, where $0 \leq p \leq 1$. Then, we have

$$
\begin{aligned}
& \operatorname{Pr}[(\bar{c}, \bar{c}) \mid(\mathrm{G}, \mathrm{G})]=\operatorname{Pr}[(\underline{c}, \underline{c}) \mid(\mathrm{G}, \mathrm{G})]=\frac{1+\rho}{4} \\
& \operatorname{Pr}[(\bar{c}, \underline{c}) \mid(\mathrm{G}, \mathrm{G})]=\operatorname{Pr}[(\underline{c}, \bar{c}) \mid(\mathrm{G}, \mathrm{G})]=\frac{1-\rho}{4}
\end{aligned}
$$

In all other choices of input specifications, we have

(2) $\operatorname{Pr}[(\bar{c}, \bar{c}) \mid(\mathrm{A}, \mathrm{B})]=\operatorname{Pr}[(\underline{c}, \underline{c}) \mid(\mathrm{A}, \mathrm{B})]=\operatorname{Pr}[(\bar{c}, \underline{c}) \mid(\mathrm{A}, \mathrm{B})]=\operatorname{Pr}[(\underline{c}, \bar{c}) \mid(\mathrm{A}, \mathrm{B})]=1 / 4$, where $(A, B)=\left(G, S_{2}\right),\left(S_{1}, G\right)$, or $\left(S_{1}, S_{2}\right)$.

One natural interpretation of the model is that we take the event of a low cost realization as an innovation. Upstream firms have discretion over what kind of innovations to pursue. Choosing a generalized input specification can be considered as devoting their innovation resources to an innovation that can be used by both downstream firms. Choosing a specialized input specification amounts to concentrating on the improvement of inputs that is more important to one of the two downstream firms. ${ }^{12}$ For instance, software developers have discretion over which platform to support (Church and

\footnotetext{
${ }^{10}$ The randomness of the cost realizations can also be due to the uncertainty in innovation. In this case, it is well known that similar scientific advances are often made more than one research teams working independetly of one another, that is, the probabilitiy of discoveries are highly correlated across research teams when they are engaged in similar projects. Merton (1961) calls this type of phenomenon "multiples."

"More generally, we could assume that production of inputs with different specifications entails less correlated cost structure without qualitatively affecting the main results.

${ }_{12}$ See Baldwin (1983) and Choi and Yi (1996) for an explicit analysis of R\&D incentives in the context of vertical merger.
} 
Gandal, 1995). ${ }^{13}$ They can spend resources to an area that can be portable to either platform or exclusively focus on one platform. In this regard, it is interesting to note that Microsoft has been alleged to be neglectful of the development of application software for the Macintosh operating system (Gleick, 1995). ${ }^{14}$

We further assume that there is a competitive fringe that supplies the generalized input at the cost of $\bar{c}$. As it will be clear later, this assumption is not crucial for our analysis and is made for expository convenience. The existence of fringe firms can serve as a lid on the price of inputs regardless of the upstream firms' input specificity choices and cost realizations. If we interpret the low cost realization as an innovation, we can think of an initial situation where many firms are willing to supply at the cost of $\bar{c}$, which can serve as a competitive fringe. Among them, only two firms, $\mathrm{U} 1$ and $\mathrm{U} 2$, are capable of making cost-reducing innovations.

Recall that $q(x, y)$ denotes the equilibrium output for a downstream firm when it pays the input price of $x$ and the rival firm pays $y$. Since one unit of input is needed to produce one unit of final product, we can use $q(x, y)$ to obtain the derived demand for upstream firms. For instance, suppose that both upstream firms supply the generalized input. In this case, if $U_{i}$ and $U_{j}$ sell the input at the price of $x$ and $y$, respectively, $i \neq j$, and $x<\max (y, \bar{c})$, then, Ui's demand function can be written as $2 q(x, x)$ while Uj's demand is zero. Ui's profit is given by $(x-c) 2 q(x, x)$ if its production cost is $c$. In contrast, if $U_{i}$ supplies a specialized input for $\mathrm{Di}$, then, its demand function when it charges $\mathrm{x}$ can be written as $q(x, y)$, when $U_{i}$ is the lowest price supplier for $D_{i}$ and $D_{j}$ pays an input price of $y$. Ui's profit in this case is $(x-c) q(x, y)$ when its production cost is $c$. These profit functions for upstream firms are assumed to be well-behaved concave functions. To

\footnotetext{
${ }^{13}$ In this respect, a decision to support only one hardware format is similar to tying in its exclusionary effect in that other hardware vendors of competing formats are foreclosed. For an analysis of tying as an exclusionary device see Whinston (1990) and Choi (1996). Church and Gandal (1995) also discuss the relationship between compatibility and tying decisions in their foreclosure effects.

${ }^{14}$ In other contexts, it may be more appropriate that the probability of low cost realization is higher for a spocialized input. Allowing this possibility does not change the qualitative results of the paper and only makes the main effects of vertical integration less transparent.
} 
abstract from the tedious process of deriving the monopolistic input supplier's optimal pricing strategy, we make the following assumption.

Assumption 2.

$$
\left.\frac{d(x-\underline{c}) 2 q(x, x)}{d x}\right|_{x=\bar{c}}>0 \text { and }\left.\frac{\partial(x-\underline{c}) q(x, y)}{\partial x}\right|_{x=\bar{c}}>0 \text { for any } \mathrm{y} \in[\underline{c}, \bar{c}]
$$

Assumption 2 ensures that the competitive pressure of fringe firms is always binding. In other words, the monopolistic supplier of inputs will always have incentive to set a higher price than $\bar{c}$ in the absence of fringe firms. This implies that when there is only one firm with the cost of $\underline{c}$, it will set the price of the input at $\bar{c}$ (minus $\varepsilon$ ). This condition is satisfied if the difference between $\underline{c}$ and $\bar{c}$ is not too large. If we interpret the low cost realization event as an innovation, Assumption 2 is also referred to as a nondrastic innovation in the R\&D literature.

\section{Assumption 3.}

$$
\pi(\underline{c}, \bar{c})+\pi(\bar{c}, \underline{c})>\pi(\underline{c}, \underline{c})+\pi(\bar{c}, \bar{c})
$$

Assumption 3 states that the aggregate industry profit is higher when the downstream firms have asymmetric cost structures with their mean costs constant. This assumption is satisfied in a variety of oligopoly models since competition tends to be more intense, and as a result, more industry rent is dissipated when firms are more symmetrically positioned in terms of costs (Tirole, 1988, p. 223).

To analyze potential anti-competitive effects of vertical foreclosure, we consider the following five stage game. The game structure closely follows O-S-S to facilitate comparison. ${ }^{15}$ In the first stage, the downstream firms bid to acquire one of the upstream suppliers. As in O-S-S, if there is a merger, we assume that it occurs between U1 and D1. In the second stage, we allow the possibility of a counter-merger between U2 and D2, provided there is a merger between U1 and D1. In the third stage, each upstream firm decides on the type of inputs ( $G$ or $S_{i}$ ) that will be supplied. The choice of input

${ }^{15}$ See also Hart and Tirole (1990) for detailed comments on the timing of the game. 
specifications is considered irreversible at later stages. Our main emphasis is on how the vertical structure of the industry affects the choice of input specifications. In the fourth stage, input costs are realized depending on the choices of input specifications made by the upstream firms. Note that the distribution of cost realizations depends on the choice of input specifications. In particular, we assume that producing the same type of input causes their production costs to be positively correlated. Given cost realizations and the industry structure, input prices for the downstream firms are determined. In the final stage, downstream prices are chosen, given input prices. To derive the subgame perfect equilibrium of the game, we proceed by backward induction.

\section{B. Input Specificity under Various Vertical Structures}

In this subsection, we analyze the equilibrium choice of input specifications under two alternative vertical structures - nonintegration (NI) and partial (vertical) integration (PI). We are most interested in how vertical integration by $\mathrm{U} 1$ and $\mathrm{D} 1$ changes the equilibrium choices of input specification. The case of input choices under full integration (FI) will be considered when we analyze U2 and D2's incentive to countermerge in the face of the U1-D1 merger.

\section{Nonintegration (NI)}

We first analyze the incentives for upstream firms with respect to input specification when both upstream firms are independent and vertically separated from downstream firms. To analyze these incentives, we need to derive the expected profits for the upstream firms under different configurations of input choices. As noted earlier, there are four possible configurations to consider: $(G, G),\left(S_{1}, S_{2}\right),\left(S_{1}, G\right)$ and $\left(G, S_{2}\right)$.

Case I. (G, G): In this case, the probability of each cost realization is given by Eq. (1). Under this regime, both upstream firms can supply both downstream firms. Bertrand 
competition between upstream firms imply that an upstream firm i can have profits only when it is a low cost producer in comparison to the other firm $j$ who is a high cost producer, i.e., $\mathrm{c}_{\mathrm{i}}=\underline{c}$ and $\mathrm{c}_{\mathrm{j}}=\bar{c}, \mathrm{i} \neq \mathrm{j}$. In this case, due to Assumption 2 , firm $\mathrm{i}$ supplies to both downstream firms at the price of $m_{i}=\bar{c}$, and earns the profit of $2 \bar{\phi}$, where $\bar{\phi}=$ $(\bar{c}-c) q(\bar{c}, \bar{c})$. The probability of this event is given by $(1-\rho) / 4$. In other events, the firm earns zero profit due to competition. Therefore, the expected profit for each upstream firm under $(G, G)$ is given by:

$$
\Pi_{l i}^{N I}(\mathrm{G}, \mathrm{G})=\frac{1-\rho}{4}(2 \bar{\phi}), \text { where } \bar{\phi}=(\bar{c}-\underline{c}) q(\bar{c}, \bar{c}) \text {. }
$$

For future reference, we also derive the expected profit for downstream firms. Under (G, G), the input prices will be $\bar{c}$ for all cost realizations except $(\underline{c}, \underline{c})$, in which case input prices are driven to $\underline{c}$ due to Bertrand competition. Therefore, the expected profit for each downstream firm is given by

$$
\Pi_{D i}^{N}(\mathrm{G}, \mathrm{G})=\frac{1+\rho}{4} \pi(\underline{c}, \underline{c})+\left(1-\frac{1+\rho}{4}\right) \pi(\bar{c}, \bar{c})
$$

Case II. $\left(S_{1}, S_{2}\right)$ : Under this regime, the two upstream firms do not compete with each other because each upstream firm can supply its inputs only to the downstream firm to which its input is dedicated. In this case, the profit for each upstream firm is independent of the cost realization of the rival firm. The only competition comes from the fringe who supplies the generalized input at $\bar{c}$. Each upstream firm earns profits only when it is a low cost producer. Note that under this regime, each upstream firm can earn positive profits even if the other upstream firm's cost is also low. Therefore, each firm's expected profit under this regime is given by:

$$
\prod_{U i}^{N I}\left(\mathrm{~S}_{1}, \mathrm{~S}_{2}\right)=(\bar{c}-\underline{c}) \mathrm{q}(\bar{c}, \bar{c}) / 2=\bar{\phi} / 2
$$

When both upstream firms provide specialized inputs, both of them are monopolistic suppliers. As a result, the input prices for both downstream firms are given by $\bar{c}$, regardless of the cost realizations for upstream firms.

$$
\Pi_{D i}^{N}\left(\mathrm{~S}_{1}, \mathrm{~S}_{2}\right)=\pi(\bar{c}, \bar{c})
$$


Case III. Mixed input specifications $\left(S_{1}, G\right)$ : This case considers the situation when Ul chooses the specialized input for D1 whereas U2 produces the generalized input. In this case, both $\mathrm{U} 1$ and $\mathrm{U} 2$ compete for the business of D1. However, D2 can be served only by U2. Therefore, U2 has monopoly power over D2, which implies that D2's marginal cost is always $\bar{c}$. In particular, even when both upstream firms have the low cost, D2 is supplied at the price of $\bar{c}$ while Dl's input cost is driven down to $\underline{c}$ due to competition.

We have

$$
\begin{aligned}
\Pi_{v 1}^{N}\left(\mathrm{~S}_{1}, \mathrm{G}\right) & =(\bar{c}-\underline{c}) \mathrm{q}(\bar{c}, \bar{c}) / 4=\bar{\phi} / 4 \\
\Pi_{U 2}^{N}\left(\mathrm{~S}_{1}, \mathrm{G}\right) & =[(\bar{c}-\underline{c}) \mathrm{q}(\bar{c}, \underline{c}) / 4]+[2(\bar{c}-\underline{c}) \mathrm{q}(\bar{c}, \bar{c}) / 4] \\
& =\frac{1}{4} \underline{\phi}+\frac{1}{4}(2 \bar{\phi}), \text { where } \underline{\phi}=(\bar{c}-\underline{c}) \mathrm{q}(\bar{c}, \underline{c})
\end{aligned}
$$

Note that $\underline{\phi}=(\bar{c}-\underline{c}) q(\bar{c}, \underline{c})<(\bar{c}-\underline{c}) q(\bar{c}, \bar{c})=\bar{\phi}$, due to Assumption 1. The first term of U2's profit comes when both upstream firms have the low production cost, whereas the second term is its profit when it is the only one which has the low production cost.

$$
\text { Under }\left(S_{1}, G\right) \text {, the downstream firms' profits are given by }
$$

(9) $\quad \Pi_{D 1}^{N}\left(\mathrm{~S}_{1}, \mathrm{G}\right)=\frac{1}{4} \pi(\underline{c}, \bar{c})+\left(1-\frac{1}{4}\right) \pi(\bar{c}, \bar{c})$

$$
\Pi_{D 2}^{N}\left(S_{1}, G\right)=\frac{1}{4} \pi(\bar{c}, \underline{c})+\left(1-\frac{1}{4}\right) \pi(\bar{c}, \bar{c})
$$

Note that $D 1$ is better off while D2 is worse off when one of the upstream firms tailor its input specification for D1. This externality will form the basis of the analysis that follows.

Case IV. Mixed input specifications ( $\left.G, S_{2}\right)$ : This is the mirror image of Case III.

By comparing the upstream firms' expected payoffs under various input specifications, we can derive the following proposition. 
Proposition 1. When both upstream firms are nonintegrated, the equilibrium in the choices of input specification can be characterized in the following way:

(i) if $\rho \leq 1 / 2$, (G, G) is the unique Nash equilibrium,

(ii) if $\rho>1 / 2$, there exist multiple equilibria. There are two asymmetric pure strategy equilibria, which are $\left(S_{1}, G\right)$ and $\left(G, S_{2}\right)$. In addition, there is a symmetric mixed strategy equilibria in which $U i$ chooses $S_{i}$ with probability of $\mu=1-\frac{\underline{\phi}}{(2 \rho-1) \bar{\phi}+\underline{\phi}}$.

The intuition for Proposition 1 is simple. When upstream firms compete with each other in Bertrand competition, Ui can get positive profits only when it has the low cost realization while $U_{j}$ has the high cost realization, $i \neq j$. The probability of this asymmetric cost realization is reduced as the correlation parameter $\rho$ increases. In this sense, $\rho$ can be considered as a parameter representing the intensity of competition. When $\rho$ is low ( $\rho$ $\leq 1 / 2$ ), choosing $\mathrm{G}$ is a dominant strategy for both upstream firms. The reason for this is that choosing a specialized input is too costly a choice because it entails giving up half of the potential market. As $\rho$ increases further than $1 / 2$, however, competition becomes too intense. This creates an incentive for one of the upstream firms to choose a different input specification to relax competition by reducing cost correlation. As a result, $(G, G)$ cannot be sustained as a Nash equilibrium if $\rho$ is too high $(\rho>1 / 2)$.

Note that relaxing competition by reduced cost correlation requires that only one firm switch to a specialized input. Since choosing a specific input involves the cost of giving up the opportunity to serve the other half of the market, this implies that the choice of specific input is analogous to the provision of a public good; while the benefit of reduced correlation is shared by both upstream firms, the cost of it is solely borne by the firm switching to a specialized input. This implies that from the collective viewpoint of the upstream firms, their costs tend to be too correlated in the market outcome, that is, they choose the same specification of input (the generalized input) too often (Dasgupta 
and Maskin, 1987). ${ }^{16}$ This also explains why the input specification game has the payoff matrix of a chicken game when $\rho>1 / 2$, with two asymmetric pure strategy equilibria and one symmetric mixed strategy equilibrium.

In the rest of the paper, we focus mainly on the case where $\rho \in[0,1 / 2]$ for two reasons. First, it enables us to avoid the issue of multiple equilibria. Second, and more importantly, the issue of vertical integration-induced foreclosure does not arise when $\rho$ $>1 / 2$ because vertical foreclosure is already present, even with independent suppliers. Thus, we explore how vertical integration can change the incentives to supply a specialized input when both upstream firms supply the generalized input and compete with each other under NI.

At this stage, it is enlightening to consider the effect of the U1's choice of $S_{1}$ on other firms. U2 benefits from U1's choice of specific input through two channels. First, it exercises monopoly power over D2 due to U1's commitment to supply only to D1. Second, cost correlation is reduced across the two upstream firms. As pointed out earlier, D2 loses because its input price is raised due to U1's withdrawal as a potential supplier of its input. Most importantly, Dl gains because its rival firm's cost is raised (Salop and Scheffman, 1983). The recognition of these externalities will be crucial to understand the incentives to choose a specialized input when one of the upstream firms is vertically integrated; vertical integration provides a mechanism to internalize the positive externality (the benefit from raising the rivals' costs) on D1 of choosing $S_{1}$.

\section{Partial Integration (PI)}

Let us assume that the industry has a partially integrated structure, i.e., U1 and D1 have vertically integrated whereas $\mathrm{U} 2$ and $\mathrm{D} 2$ remain independent. We assume that vertical integration does not entail any changes in the underlying production technology. ${ }^{17}$

\footnotetext{
${ }^{16}$ It can be easily verified that the joint profits of upstream firms increase when one of the firms choose a specialized input if $\rho>\frac{1}{4}\left(1-\frac{\phi}{6}\right)$.
} 
Within the vertically integrated firm (U1-D1), U1 supplies its output at the internal transfer price equal to its marginal cost of production. After integration, the decision on input specification will be made based on its impact on combined profits of U1-D1. We can write the profit for the integrated firm under various configurations of input specification in the following way.

Suppose that both integrated firm and nonintegrated upstream firm $\mathrm{U} 2$ have chosen to produce the generalized input that can be used by both downstream firms. In this case, if the cost realization is $(\underline{c}, \underline{c})$, both downstream firms will have marginal costs of $\underline{c}$, and the integrated firm has the profit of $\pi(\underline{c}, \underline{c})$. The probability of this event is $(1+\rho) / 4$ because they produce the same type of input. If the cost realization is $(\underline{c}, \bar{c})$, which occurs with probability of (1-p)/4, the integrated downstream firm produces at the cost of $\underline{c}$ whereas the nonintegrated downstream firm D2's marginal cost is $\bar{c}$. Therefore, the integrated firm has the profit of $\pi(\underline{c}, \bar{c})$ in the final product market. In addition, the integrated firm supplies to D2 at the price of $\bar{c}$ and earns $\underline{\phi}=(\bar{c}-\underline{c}) q(\bar{c}, \underline{c})$ in the input market. If the cost realization is $(\bar{c}, \underline{c})$ or $(\bar{c}, \bar{c})$, both downstream firms' marginal costs are $\bar{c}$, and the integrated firm earns the profits of $\pi(\bar{c}, \bar{c})$. Therefore, the integrated firm's expected profit under $(G, G)$ can be written as

$$
\Pi_{v_{1-D 1}}^{P I}(\mathrm{G}, \mathrm{G})=\frac{1+\rho}{4} \pi(\underline{c}, \underline{c})+\frac{1-\rho}{4}[\pi(\underline{c}, \bar{c})+\underline{\phi}]+\frac{1}{2} \pi(\bar{c}, \bar{c})
$$

Note that in writing (11), we, unlike O-S-S, do not assume the ability of the integrated firm to make commitments not to supply to $D 2$ or to a specific price. As a result, when both upstream firms have the low cost, the input price to $D 2$ will be driven to $\underline{c}$ due to competition.

\footnotetext{
${ }^{17}$ In other words, we abstract from internal organization aspects of vertical integration that may induce different production costs of inputs across integrated and nonintegrated upstream firms through various incentive effects. A recent literature on the internal organization of the firm, for instance, emphasizes how vertical integration affects the incentive to make a relationship-specific investment by eliminating the possibility of post-contractual opportunistic behavior (Klein, Crawford, and Alchian, 1978) or through the allocation of residual rights of control over assets (Grossman and Hart, 1986).
} 
Now suppose that the integrated firm, U1-D1, chooses $S_{1}$ whereas $U 2$ chooses $G$. Then, the integrated firm cannot sell to D2 even when it is the only low cost producer. Due to the lack of competition, the input cost for D2 is always $\bar{c}$. Since there is no profit for U1, the integrated firm's expected profit under $\left(S_{1}, G\right)$ is

$$
\Pi_{U 1-D 1}^{P I}\left(S_{1}, G\right)=\frac{1}{2} \pi(\underline{c}, \bar{c})+\frac{1}{2} \pi(\bar{c}, \bar{c})
$$

Proceeding in the same way, we can derive the expected profits for the integrated firm under alternative input specifications.

$$
\begin{aligned}
& \Pi_{U 1-D 1}^{P I}\left(\mathrm{G}, \mathrm{S}_{2}\right)=\frac{1}{4} \pi(\underline{c}, \underline{c})+\frac{1}{4}[\pi(\underline{c}, \bar{c})+\underline{\phi}]+\frac{1}{2} \pi(\bar{c}, \bar{c}) \\
& \Pi_{U 1-D 1}^{P I}\left(\mathrm{~S}_{1}, \mathrm{~S}_{2}\right)=\frac{1}{2} \pi(\underline{c}, \bar{c})+\frac{1}{2} \pi(\bar{c}, \bar{c})
\end{aligned}
$$

Similarly, the expected profit for the nonintegrated upstream firm U2 can be also written as:

$$
\begin{aligned}
& \Pi_{U_{2}}^{P I}(\mathrm{G}, \mathrm{G})=\frac{1-\rho}{4}(2 \bar{\phi}) \\
& \Pi_{U_{2}}^{P I}\left(\mathrm{~S}_{1}, \mathrm{G}\right)=\frac{1}{4}(2 \bar{\phi})+\frac{1}{4} \underline{\underline{ }} \\
& \Pi_{U 2}^{P I}\left(\mathrm{G}, \mathrm{S}_{2}\right)=\frac{1}{4} \bar{\phi} \\
& \Pi_{U_{2}}^{P I}\left(\mathrm{~S}_{1}, \mathrm{~S}_{2}\right)=\frac{1}{4} \bar{\phi}+\frac{1}{4} \underline{\phi}
\end{aligned}
$$

Now let us consider the incentives for the integrated firm, U1-D1, to deviate from (G, G) configuration.

$$
\begin{aligned}
& \Pi_{U 1-D 1}^{P I}\left(S_{1}, G\right)-\Pi_{U 1-D 1}^{P I}(G, G) \\
& =\frac{1+\rho}{4}[\pi(\underline{c}, \bar{c})-\pi(\underline{c}, \underline{c})]-\frac{1-\rho}{4} \underline{\phi}
\end{aligned}
$$

The U1-Dl's incentive to switch to a specialized input under vertical integration consists of two components. The first term represents the impact of choosing the specialized input on raising rival firms' costs through its commitment to not supply to D2. The second term is the negative effect of limiting U1's customer base by not supplying to D2. Let $\rho^{*}$ be the (unique) critical value which makes $\prod_{U 1-D 1}^{P I}\left(S_{1}, G\right)=\prod_{U 1-D 1}^{P I}(G, G)$. Then, we have 


$$
\rho^{*}=\frac{\phi-[\pi(\underline{c}, \bar{c})-\pi(\underline{c}, \underline{c})]}{\underline{\phi}+[\pi(\underline{c}, \bar{c})-\pi(\underline{c}, \underline{c})]}
$$

With modified incentives accompanying vertical integration, we can derive the following proposition.

Proposition 2. Let us restrict our attention to the parameter region where $(G, G)$ is the unique equilibrium under nonintegration, i.e., $\rho \in[0,1 / 2]$. Then, we have the following characterization of equilibrium choices of input specification under partial integration.

(i) if $\rho>\rho *,\left(S_{1}, G\right)$ is the unique equilibrium,

(ii) if $\rho<\rho^{*},(G, G)$ is the unique equilibrium.

(iii) $\left(S_{1}, S_{2}\right)$ and $\left(G, S_{2}\right)$ cannot be sustained as an equilibrium.

Proof. Simple comparisons of expected profits under various input specifications.

Let us define a set of correlation coefficients, $\Sigma=$ [م, 1/2], which may be called the vertical foreclosure set, where $\varrho=\max \left(\rho^{*}, 0\right)$. Then, Proposition 2 informs us that when $\rho \in \Sigma$, the upstream firm in the integrated structure changes its input specification from the general input to the specific input (dedicated to its own downstream firm), thereby withdrawing from the input market for the rival downstream firm. As a result, the nonintegrated downstream firm (D2) loses trading opportunities with the integrated upstream firm (U1) and vertical foreclosure occurs. The reason for the incentive change with vertical integration can be explained by the internalization of the benefit to D1 of raising the rival firm's costs (Salop and Scheffman, 1983), which is given by $[\pi(\underline{c}, \bar{c})-\pi(\underline{c}, \underline{c})]$. When $\mathrm{U} 1$ and $\mathrm{D} 1$ remain as independent firms, this positive externality is not accounted for when $U 1$ decides on its input specification. As an integrated firm, this benefit is taken into consideration in its input specification decision.

The non-emptiness of the set $\Sigma$ is crucial for the input specialization-induced market foreclosure to occur with partial integration. The set also needs to be reasonably 
large for the type of market foreclosure considered in this paper to have practical importance. Hence, it is worthwhile to explore the plausibility of such a set. The examination of Eq. (17) reveals that the existence and the size of the set $\Sigma$ depends on the relative magnitudes of $\underline{\phi}$ and $[\pi(\underline{c}, \bar{c})-\pi(c, \underline{c})]$. In particular, $\rho^{*}$ decreases with $[\pi(\underline{c}, \bar{c})-\pi(\mathcal{c}, \underline{c})]$, which implies that the set $\Sigma$ expand as $[\pi(\underline{c}, \bar{c})-\pi(\mathcal{c}, \underline{c})]$ increases. This confirms our intuition that the incentive to choose a specialized input with vertical integration increases as the benefit of raising the rival firm's costs increases.

More specifically, for the standard models of oligopoly we can show the following (see the Appendix). In both (i)Cournot competition with homogeneous products and linear demand curve $(\mathrm{P}=\mathbf{a}-\mathrm{Q})$ and (ii)Hotelling-type price competition with differentiated products, $\rho^{*}$ cannot exceed $1 / 5$, thereby ensuring that the set $\Sigma$ is at least larger than [1/5, 1/2]. When we define $\Delta=\bar{c}-\underline{c}$, we can also show that $\rho^{*}$ decreases as $\Delta$ increases in both cases, signifying the fact the effect of raising rival firm's cost increases with $\Delta^{18}$ With the Hotelling model, $\rho^{*}$ also decreases as $t$ (transportation cost parameter) decreases. Since $t$ can be considered as a measure of competitiveness, this implies that raising the rival firm's cost becomes more important as the degree of competitiveness at the downstream level is intensified. Furthermore, we can show that (i) if $\Delta \geq a / 7$ with Cournot competition, where a is the demand intercept and (ii)if $\Delta t \geq 3 / 4$ with Hotelling competition, we have $\rho^{*} \leq 0$, which implies that market foreclosure occurs for the whole parameter space we consider, i.e., $\Sigma=[0,1 / 2]$.

For $\Sigma$ to be an empty set, it is required that $\rho^{*}>1 / 2$, or $\underline{\phi}>3[\pi(\underline{c}, \bar{c})-\pi(\mathcal{c}, \underline{c})]$, which is a quite stringent condition to satisfy. For instance, from our discussion above, we know that this condition is never satisfied for a Cournot competition with linear demand or for a Hotelling-type price competition. Therefore, we conclude that for almost

\footnotetext{
${ }^{18}$ Note that $\Delta$ measures the increase in the rival downstream firm' $s$ input acquisition cost due to vertical foreclosure.
} 
all conceivable oligopoly models of downstream competition, there exists a set $(\Sigma)$ that induces market foreclosure with partial integration.

\section{Incentives for Anti-competitive Vertical Integration}

In this subsection, we analyze the incentive to vertically integrate. If vertical integration does not involve the changes in the types of inputs produced by the merged firms, there is no vertical foreclosure on D2, and its only effect is the elimination of double marginalization for the U1-Dl pair. In most standard oligopoly models, this effect tends to increase total output and reduce prices for consumers. As a result, social welfare increases. To focus on potential anti-competitive effects of vertical integration, we concentrate on the case where the equilibrium input specification is changed from $(G, G)$ to $\left(S_{1}, G\right)$ after vertical integration, that is, $\rho \in \Sigma=[0,1 / 2]$.

Then, the condition that vertical integration is profitable is given by:

$$
\begin{aligned}
\mathrm{G}^{\mathrm{V}} & =\prod_{U 1-D 1}^{P l}\left(\mathrm{~S}_{1}, \mathrm{G}\right)-\left[\Pi_{U_{1}}^{N}(\mathrm{G}, \mathrm{G})+\Pi_{D 1}^{N}(\mathrm{G}, \mathrm{G})\right] \\
= & \frac{1}{2} \pi(\underline{c}, \bar{c})+\frac{1}{2} \pi(\bar{c}, \bar{c})-\left[\frac{1-\rho}{4}(2 \bar{\phi})+\frac{1+\rho}{4} \pi(\underline{c}, \underline{c})+\left(1-\frac{1+\rho}{4}\right) \pi(\bar{c}, \bar{c})\right]
\end{aligned}
$$

$>0$

By rearranging terms, the condition for profitable partial integration (PI) can be rewritten as

$$
\mathrm{G}^{\mathrm{n}}=\frac{1+\rho}{4}[\pi(\underline{c}, \bar{c})-\pi(\underline{c}, \underline{c})]+\frac{1-\rho}{4}[\pi(\underline{c}, \bar{c})-(\pi(\bar{c}, \bar{c})+\bar{\phi})]-\frac{1-\rho}{4} \bar{\phi}>0
$$

The effect of vertical integration on the combined profits of $\mathrm{U} 1$ and $\mathrm{D} 1$ comprises of three elements. The first term on the RHS of (19) is the positive effect of raising the rival firm's costs when both firms have a low cost realization. The second term is the effect of eliminating double marginalization between $\mathrm{U} 1$ and $\mathrm{D} 1$ when $\mathrm{U} 1$ has a lower cost realization and U2 has a higher cost realization. Before vertical integration, D1 is supplied at the price of $\bar{c}$ by U1. After vertical integration, U1 transfers input internally to D1 at the marginal cost $\underline{c}$. In contrast to the successive monopoly case analyzed by Spengler 
(1950), this effect, in general, is ambiguous in the oligopoly. It depends on the cost differential between $\underline{c}$ and $\bar{c}$ and on whether the strategic variables are strategic complements or substitutes. The third term is the negative effect of giving up part of the market by producing a specialized input with vertical integration. Therefore, we can conclude that if the beneficial effect of raising the rival firm's costs is sufficiently important relative to the loss of upstream business, there can be an anti-competitive vertical merger. If the nature of downstream competition is strategic substitutes, then the incentive for vertical merger will be reinforced by the elimination of double marginalization. 'If the strategic variable is strategic complements, the effect of the second term will weaken the incentive to vertically merge if the difference between $\underline{c}$ and $\bar{c}$ is small, while it will strengthen it if the difference is large [see Bonanno and Vickers, 1988].

As emphasized by the Chicago school and O-S-S, to have a complete theory of anti-competitive mergers, we also need to analyze the incentive to countermerge by the remaining independent firms, which can undo the initial anti-competitive effect of the merger by $\mathrm{U} 1$ and $\mathrm{D} 1$.

\section{Incentive for Counter-merger}

In this section, we analyze the incentive for D2 to countermerge with U2 in the face of the vertical merger between $\mathrm{U} 1$ and $\mathrm{D} 1$. There will be a counter-merger if $\mathrm{U} 2$ and D2, as an integrated firm, can make more profits than the combined profits they can earn as separate identities. We know that after U1-D1 merger, the merged firm chooses $S_{1}$ whereas $U 2$ chooses $G$, if $\rho \in \Sigma=[\varrho, 1 / 2]$. Therefore, without a counter-merger, $U 2$ and D2's expected profits as separate entities can be written as:

$$
\begin{aligned}
& \Pi_{U_{2}}^{P l}\left(S_{1}, G\right)=\frac{1}{4}(2 \bar{\phi})+\frac{1}{4} \phi \\
& \Pi_{D 2}^{P J}\left(S_{1}, G\right)=\frac{1}{2} \pi(\bar{c}, \underline{c})+\frac{1}{2} \pi(\bar{c}, \bar{c})
\end{aligned}
$$


To derive the equilibrium profits after counter-merger (CM), we have to first analyze the equilibrium choice of input specification under full integration (FI). When both firms are vertically integrated, U2-D2's expected profit under each input specification configuration is as follows:

$$
\begin{aligned}
& \Pi_{\mathrm{U} 2-\mathrm{D} 2}^{\mathrm{F}}(\mathrm{G}, \mathrm{G})=\frac{1+\rho}{4} \pi(\underline{c}, \underline{c})+\frac{1-\rho}{4}[\pi(\underline{c}, \bar{c})+\underline{\phi}]+\frac{1-\rho}{4} \pi(\bar{c}, \underline{c})+\frac{1+\rho}{4} \pi(\bar{c}, \bar{c}) \\
& \Pi_{\mathrm{U} 2-\mathrm{D} 2}^{\mathrm{F}}\left(\mathrm{S}_{1}, \mathrm{G}\right)=\frac{1}{4} \pi(\underline{c}, \underline{c})+\frac{1}{4}[\pi(\underline{c}, \bar{c})+\underline{\phi}]+\frac{1}{4} \pi(\bar{c}, \underline{c})+\frac{1}{4} \pi(\bar{c}, \bar{c}) \\
& \Pi_{\mathrm{U} 2-\mathrm{D} 2}^{\mathrm{F}}\left(\mathrm{G}, \mathrm{S}_{2}\right)=\Pi_{\mathrm{U} 2-\mathrm{D} 2}^{\mathrm{F}}\left(\mathrm{S}_{1}, \mathrm{~S}_{2}\right)=\frac{1}{4} \pi(\underline{c}, \underline{c})+\frac{1}{4} \pi(\underline{c}, \bar{c})+\frac{1}{4} \pi(\bar{c}, \underline{c})+\frac{1}{4} \pi(\bar{c}, \bar{c})
\end{aligned}
$$

Under full integration (FI), therefore, $(G, G)$ is once again the Nash equilibrium in input specifications if the following condition is satisfied:

$$
\begin{aligned}
& \Pi_{\mathrm{Ul}-\mathrm{Dl}}^{\mathrm{FI}}(\mathrm{G}, \mathrm{G})-\Pi_{\mathrm{Ul}-\mathrm{Dl}}^{\mathrm{FI}}\left(\mathrm{S}_{1}, \mathrm{G}\right) \\
& =\frac{\rho}{4}\{[\pi(\underline{c}, \underline{c})+\pi(\bar{c}, \bar{c})]-[\pi(\underline{c}, \bar{c})+\pi(\bar{c}, \underline{c})]\}+\frac{1-\rho}{4} \underline{\phi}>0
\end{aligned}
$$

Let us define $\rho^{* *}$ be the unique critical value which makes $\Pi_{\mathrm{Ul}-\mathrm{Dl}}^{\mathrm{Fl}}(G, G)=\Pi_{\mathrm{Ul}-\mathrm{Dl}}^{\mathrm{FI}}\left(S_{1}, G\right)$, i.e.,

$$
\rho^{* *}=\frac{\underline{\phi}}{\underline{\phi}+[\pi(\underline{c}, \bar{c})-\pi(\underline{c}, \underline{c})]-[\pi(\bar{c}, \bar{c})-\pi(\bar{c}, \underline{c})]}(>0)
$$

By conducting an analysis similar to the cases of nonintegration and partial integration, we can state the following.

Proposition 3. Under full integration, the equilibrium in the choices of input specification can be characterized in the following way:

(i) if $\rho<\rho^{* *},(G, G)$ is the unique Nash equilibrium,

(ii) if $\rho>\rho^{* *}$, there exist multiple equilibria. There are two asymmetric pure strategy equilibria, which are $\left(S_{1}, G\right)$ and $\left(G, S_{2}\right)$. In addition, there is a symmetric mixed strategy equilibria in which Ui chooses $S_{i}$ with probability of $\mu=1-\frac{(1-\rho) \underline{\underline{\phi}}}{\rho\{\underline{\phi}+[\pi(\underline{c}, \bar{c})-\pi(\underline{c}, \underline{c})]-[\pi(\bar{c}, \bar{c})-\pi(\bar{c}, \underline{c})]\}}$. 


$$
\text { Note that } \begin{aligned}
\rho^{* *} & =\frac{\underline{\phi}}{\underline{\phi}+[\pi(\underline{c}, \bar{c})-\pi(\underline{c}, \underline{c})]-[\pi(\bar{c}, \bar{c})-\pi(\bar{c}, \underline{c})]} \\
& >\frac{\underline{\phi}-[\pi(\underline{c}, \bar{c})-\pi(\underline{c}, \underline{c})]}{\underline{\phi}+[\pi(\underline{c}, \bar{c})-\pi(\underline{c}, \underline{c})]}=\rho^{*} .
\end{aligned}
$$

Therefore, we can define a set $[\varrho, \bar{\rho}]$ as long as the set $\Sigma$ we defined earlier is non-empty, where $\bar{\rho}=\min \left(\rho^{* *}, 1 / 2\right)$. When $\rho \in[\Omega, \bar{\rho}]$, the choice of input specification is such that with partial integration the integrated firm chooses a specialized input and vertical foreclosure occurs, while in all other cases of vertical structures both upstream firms choose the generalized input.

Now suppose that $\rho \in[\Omega, \bar{\rho}]$. Then, the relevant combined profit after countermerger is $\Pi_{U 2-D 2}^{\mathrm{FI}}(G, G)$. The condition for the countermerger to not be profitable is given by:

$$
\begin{aligned}
\mathrm{G}^{\mathrm{CM}} & =\Pi_{\mathrm{U} 2 \cdot \mathrm{D} 2}^{\mathrm{FI}}(\mathrm{G}, \mathrm{G})-\left[\Pi_{U_{2}}^{P I}\left(\mathrm{~S}_{1}, \mathrm{G}\right)+\Pi_{D 2}^{P I}\left(\mathrm{~S}_{1}, \mathrm{G}\right)\right] \\
& =\frac{1+\rho}{4}[\pi(\underline{c}, \underline{c})-\pi(\bar{c}, \underline{c})]+\frac{1-\rho}{4}[\pi(\underline{c}, \bar{c})-\pi(\bar{c}, \bar{c})]-\frac{1}{4}(2 \bar{\phi})-\frac{\rho}{4} \underline{\phi}<0
\end{aligned}
$$

By rearranging Eq. (22), we can write the no counter-merger condition (NCM) as follows:

$$
\text { (NCM) } \begin{aligned}
\mathrm{G}^{\mathrm{CM}} & =\Pi_{\mathrm{U} 2-\mathrm{D} 2}^{\mathrm{FI}}(\mathrm{G}, \mathrm{G})-\left[\Pi_{v_{2}}^{P I}\left(\mathrm{~S}_{1}, \mathrm{G}\right)+\Pi_{D 2}^{P I}\left(\mathrm{~S}_{1}, \mathrm{G}\right)\right] \\
& =\frac{1}{4}\{[\pi(\underline{c}, \underline{c})-\pi(\bar{c}, \underline{c})]+[\pi(\underline{c}, \bar{c})-\pi(\bar{c}, \bar{c})]\} \\
& -\frac{\rho}{4}\{[\pi(\underline{c}, \bar{c})+\pi(\bar{c}, \underline{c})]-[\pi(\underline{c}, \underline{c})+\pi(\bar{c}, \bar{c})]\}-\left[\frac{1}{4}(2 \bar{\phi})+\frac{\rho}{4} \underline{\phi}\right]<0 .
\end{aligned}
$$

A counter-merger by the foreclosed downstream firm can eliminate double marginalization and thus, undo the foreclosure effect of the initial vertical merger between $\mathrm{U} 1$ and D1, which is represented by the first term above. Counter-merging, however, at the same time can reintroduce cost correlation between the two downstream firms. In the absence of the effect of raising the rival's costs, U1-D1 ceases to have the incentive to supply a specialized input. As a result, a counter-merger in a sense deprives U1-D1 of the 
incentives to provide the public good (reduced cost correlation) and intensifies competition, the negative effect of which is given by the second term. The third term is the loss of the upstream firm's profits due to vertical integration. Hence, the no countermerger condition (NCM) indicates that if the threat of intensified competition, parametrized by $\rho$, is sufficiently large and outweighs the benefit of preventing foreclosure effect, counter-merger can be deterred.

\section{E. Hold-out Problem?}

In this section, we analyze the bidding process through which an upstream firm is acquired by a downstream firm. To keep the analysis as close to O-S-S as possible, we consider a bidding contest in which both downstream firms bid for a designated upstream firm, U1. In particular, we are interested in whether or not U1 has an incentive to holdout in the bidding process, hoping for higher profits as an independent firm when the other upstream firm is acquired. Suppose that $\rho \in[\varrho, \bar{\rho}]$ and conditions PI and NCM are satisfied.

We know that the profit after the merger is given by $\prod_{U 1-D 1}^{P I}\left(S_{1}, G\right)=\frac{1}{2} \pi(\underline{c}, \bar{c})+$ $\frac{1}{2} \pi(\bar{c}, \bar{c})$. If $\mathrm{D} 1$ loses in the bidding, it earns $\frac{1}{2} \pi(\bar{c}, \underline{c})+\frac{1}{2} \pi(\bar{c}, \bar{c})$ because it will be denied the access to U2's input supply (see Eq. (19)). Therefore, D1 is willing to bid up to the difference between these two profit levels, i.e., $b=\frac{1}{2}[\pi(\underline{c}, \bar{c})-\pi(\bar{c}, \underline{c})]$. Since D2 has the same incentive to bid, competition will drive the acquisition price of $U 1$ up to b.

Now suppose that $\mathrm{U} 1$ refuses to be bought by the downstream firms. If $\mathrm{U} 2$ is bought by one of the downstream firms instead, $U 1$, as an independent firm, will get the profit of $\frac{1}{4}(2 \bar{\phi})+\frac{1}{4} \phi$ (see Eq. (19)). 
For U1 to not have the incentive to hold-out in the acquisition process, U1 should get $a$ higher payoff by selling at the price of $b$ rather than remaining as an independent firm. The following gives us the condition for which there will be no hold-out (NHO). $(\mathrm{NHO}) \mathrm{b}-\prod_{v_{2}}^{P J}\left(\mathrm{~S}_{1}, \mathrm{G}\right)=\frac{1}{2}[\pi(\mathcal{c}, \bar{c})-\pi(\bar{c}, \mathcal{c})]-\left[\frac{1}{4}(2 \bar{\phi})+\frac{1}{4} \phi\right]>0$

Now we have the main proposition of the paper.

Proposition 4. Suppose that $\rho \in[\varrho, \bar{\rho}]$, and conditions (PI), (NCM), and (NHO) are satisfied. Then, there is an equilibrium market foreclosure with vertical integration. The integrated upstream firm switches to the specialized input dedicated to its own downstream firm, thereby committing not to supply to the rival downstream firm.

\section{F. Welfare Effects of Vertical Merger}

The welfare consequences of a vertical merger is, in general, ambiguous due to three compounding effects on social welfare. First, a vertical merger eliminates the double marginalization problem for the merging firm. This effect is, in general, positive for social welfare. However, the foreclosure effects of a vertical merger raise the costs of the nonintegrated downstream firm and have a negative consequence on social welfare. Finally, a vertical merger reduces the correlation of input costs of the downstream firms. For a variety of oligopoly models, the increase in cost asymmetry due to a vertical merger reduces competition and is harmful for social welfare even if it is privately optimal for the firms (Tirole, 1988). In the next section, we consider explicit models of oligopoly which allow us to completely characterize the conditions for an equilibrium vertical merger and its welfare consequences.

\section{Analysis of Explicit Examples}

We demonstrate the plausibility of the anti-competitive effects of vertical 
integration with examples of a Hotelling-type spatial competition and Cournot competition in the final product market.

\section{Hotelling Competition in the Final Product Market}

Suppose that two downstream firms are located at the end points of the unit interval. Consumers are uniformly distributed along the interval. They demand only one unit of the good and have reservation values of $v$, which is assumed to be sufficiently large to ensure that the market is covered. We identify a consumer with the point in the interval which represents her ideal variety of a product. A consumer buying a product located at the distance of $x$ away from her ideal variety will incur utility loss of $t x$, in addition to the price of the good, where $t$ is a "transport" cost parameter. Then, we can derive the demand function for each downstream firm as (see Tirole, 1988, Chapter 7 for details):

$$
q^{i}\left(p_{1}, p_{2}\right)=\frac{1}{2}+\frac{p_{j}-p_{i}}{2 t}, \mathrm{i}=1,2 \text { and } \mathrm{i} \neq \mathrm{j} \text {. }
$$

Each downstream firm chooses $p_{i}$ to maximize its own profit given the other firm's price $p_{j}$ and its input price $\mathrm{m}_{\mathrm{i}}$.

$$
\operatorname{Max}\left(\mathrm{p}_{\mathrm{i}}-\mathrm{m}_{\mathrm{i}}\right)\left(\frac{1}{2}+\frac{p_{j}-p_{i}}{2 t}\right)
$$

The first order condition for firm $i$ is given by $p_{j}+c_{i}+t-2 p_{i}=0$, or

$$
p_{i}=\frac{p_{j}+c_{i}+t}{2}, i=1,2 \text { and } i \neq j .
$$

The Nash equilibrium in prices, given input prices of $m_{1}$ and $m_{2}$, can be derived by solving Eqs.(25) simultaneously:

$$
p_{i}^{*}(m)=t+\frac{2 m_{i}+m_{j}}{3}
$$

The resulting equilibrium quantities are given by

$$
q\left(m_{i}, m_{j}\right)=q\left(p_{i}^{*}(m), p_{j}^{*}(m)\right)=\frac{1}{2}+\frac{m_{j}-m_{i}}{6 t}
$$

The profits are

$$
\pi_{D_{i}}=\pi\left(m_{i}, m_{i}\right)=\left(p_{i}^{*}(m)-m_{i}\right) q\left(p_{i}^{*}(m), p_{i}^{*}(m)\right)
$$




$$
=\frac{t}{2}+\frac{m_{j}-m_{i}}{3}+\frac{\left(m_{j}-m_{i}\right)^{2}}{18 t}
$$

Using (27) and (28), we can write:

$$
\begin{aligned}
& \pi(\bar{c}, \bar{c})=\pi(\underline{c}, \underline{c})=\frac{t}{2} \\
& \pi(\bar{c}, \underline{c})=\frac{t}{2}-\frac{\Delta}{3}+\frac{\Delta^{2}}{18 t} \\
& \pi(\underline{c}, \bar{c})=\frac{t}{2}+\frac{\Delta}{3}+\frac{\Delta^{2}}{18 t} \\
& \bar{\phi}=\frac{\Delta}{2} \\
& \underline{\phi}=\frac{\Delta}{2}-\frac{\Delta^{2}}{6 t}, \text { where } \Delta=\bar{c}-\underline{c} .
\end{aligned}
$$

By substituting these values, the condition for the fringe competition to bind (Assumption 2) is given by $\alpha<3 / 2$, where $\alpha=\frac{\Delta}{t}$. With the Hotelling-type competition in the downstream market and the maintained assumption of $\alpha<3 / 2$, it can also be verified that under a partially integrated structure the integrated firm always chooses the specialized input for its downstream firm, while under full integration both upstream firms choose the generalized input for the whole parameter space we consider. In other words, we have $\rho^{*}<0$ and $\rho^{* *}>1 / 2$, which makes $[\varrho, \bar{\rho}]=[0,1 / 2]$. In addition, the no counter-merger condition (NCM) is not binding. The only constraints that are binding for an equilibrium vertical merger are (PI) and (NHO), which can be written as follows for the case of the Hotelling competition:

(PI) $\quad p<\frac{1}{3}-\frac{\alpha}{9}$

(NHO)' $\alpha>1$

Taken together, the area of the equilibrium vertical foreclosure is represented by the shaded (horizontally and vertically) area in Figure 1. Moreover, as will be shown below, the equilibrium vertical foreclosure also reduces social welfare in the vertically shaded area. 


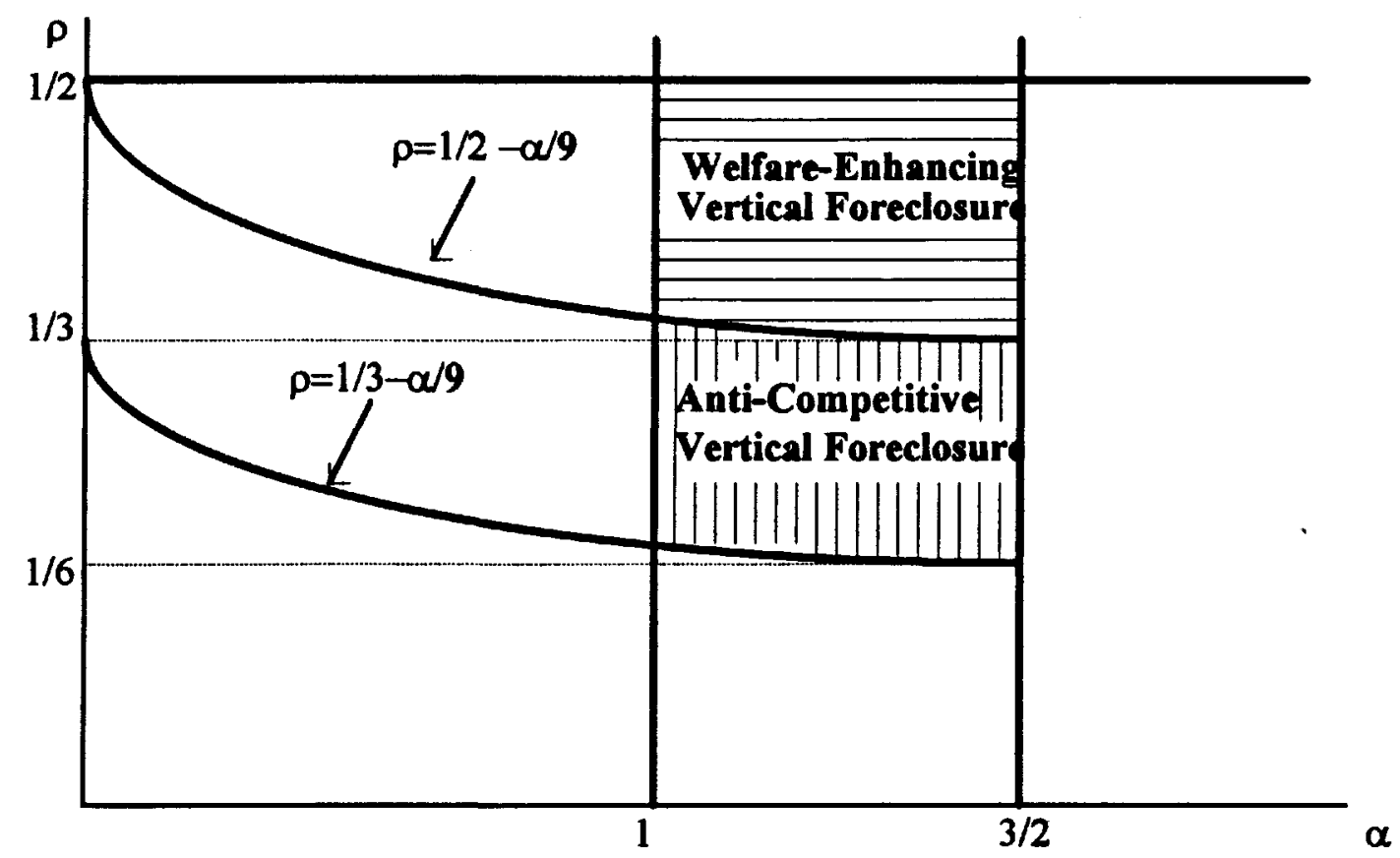

Figure 1. The Equilibrium Vertical Foreclosure

To see the welfare implications of vertical foreclosure in this model, note that there is no output effect, which makes it relatively easy to compare welfare under vertical integration and nonintegration. There are two types of costs in this model, production costs and transportation costs.

Under nonintegration, we know that both downstream firms have the same marginal cost regardless of the realizations of the upstream costs, and as a result, market share for each firm is always $1 / 2$. Therefore, the total transportation cost is given by

$$
C_{\text {Tremport }}^{N I}=2 \int_{0}^{1 / 2} t x d x=\frac{t}{4}
$$

Also, we know that inputs will be produced at the high cost of $\bar{c}$ only when both upstream firms have cost realizations of $\bar{c}$. In all other cases, inputs will be supplied by the low cost firm and the production cost of inputs will be $\underline{c}$. Therefore, the expected production cost under nonintegration is 


$$
C_{\mathrm{Pr} \text { od }}^{N \mathrm{~d}}=\frac{1+\rho}{4} \bar{c}+\left(1-\frac{1+\rho}{4}\right) \underline{c}
$$

The total cost under nonintegration is

$$
\begin{aligned}
C_{\text {Tocal }}^{N M} & =C_{\text {Tranpont }}^{N M}+C_{\text {Prod }}^{N I}=\frac{t}{4}+\frac{1+\rho}{4} \bar{c}+\left(1-\frac{1+\rho}{4}\right) \underline{c} \\
& =[t+3 \underline{c}+\bar{c}+\rho \Delta] / 4, \text { where } \Delta=\bar{c}-\underline{c} .
\end{aligned}
$$

Under a vertical merger by $\mathrm{U} 1$ and $\mathrm{D} 1$, the transportation and production costs with each cost realization can be summarized by Table 1 . For instance, consider the case where cost realization is given by $(\underline{c}, \bar{c})$. D1 and D2's marginal costs in this case are given by $\underline{c}$ and $\bar{c}$, respectively, because U1 cannot undercut U2's price due to U1's input specification tailored for D1. Thus, D1's market share is given by $s_{1}=\frac{1}{2}+\frac{\Delta}{6 t}$. Therefore, the transportation cost in this case is $\int_{0}^{4} t a d x+\int_{0}^{1-4} t x d x=\frac{t}{4}+\frac{\Delta^{2}}{36 t}$. Production costs are given by $s_{1} \underline{c}+\left(1-s_{1}\right) \bar{c}=\frac{1}{2} \bar{c}+\frac{1}{2} \underline{c}-\frac{\Delta^{2}}{6 t}$. Transportation and production costs for other cost realizations can be derived in a similar way.

\begin{tabular}{c|ccc}
\hline States of Nature & Probability & Transportation Costs & Production Costs \\
\hline$(\bar{c}, \bar{c})$ & $\frac{1}{4}$ & $\frac{t}{4}$ & $\bar{c}$ \\
$(\bar{c}, \mathrm{c})$ & $\frac{1}{4}$ & $\frac{t}{4}+\frac{\Delta^{2}}{36 t}$ & $\underline{\mathrm{c}}$ \\
$(\mathrm{c}, \bar{c})$ & $\frac{1}{4}$ & $\frac{t}{4}+\frac{\Delta^{2}}{36 t}$ & $\frac{1}{2} \bar{c}+\frac{1}{2} \mathrm{c}-\frac{\Delta^{2}}{6 t}$ \\
$(\mathrm{c}, \mathrm{c})$ & $\frac{1}{4}$ & $\frac{t}{4}$ & $\underline{\mathrm{c}}$ \\
\hline
\end{tabular}

Table 1. Transportation and Production Costs under Partial Integration

By taking the probability-weighted average, we have

$$
C_{\text {Transport }}^{P I}=\frac{t}{4}+\frac{\Delta^{2}}{72 t}
$$




$$
\begin{aligned}
& C_{\text {Prod }}^{P I}=\frac{3}{8} \bar{c}+\frac{5}{8} c-\frac{\Delta^{2}}{24 t} \\
& C_{\text {Total }}^{P I}=C_{\text {Transpon }}^{P I}+C_{\text {Prod }}^{P I}=\frac{t}{4}+\frac{3}{8} \bar{c}+\frac{5}{8} c-\frac{\Delta^{2}}{36 t}
\end{aligned}
$$

Therefore, a vertical merger by $\mathrm{Ul}$ and $\mathrm{Dl}$ is welfare-reducing if $C_{\text {Total }}^{P I}>C_{\text {Total }}^{N I}$. The condition for this is given by $\rho<\frac{1}{2}-\frac{\alpha}{9}$, where $\alpha=\frac{\Delta}{t}$.

\section{Cournot Competition with Linear Demand $(P=a-0)$ in the Final Product Market}

When the downstream firms compete in quantities, it turns out that countermerging is profitable and vertical foreclosure does not arise as in O-S-S. The intuition for this result is similar to the one provided in O-S-S. With Hotelling competition, firms' choices are strategic complements; thus, an increase in D2's costs due to foreclosure has a positive strategic effect in that it invites less aggressive behavior from its rival firm (D1). This effect mitigates the incentive for firm 2 to countermerge. In contrast, when the downstream firm competes in quantities, firms' choices constitute strategic substitutes. As a result, an increase in D2's costs has a negative strategic effect of inducing its rival firm to behave more aggressively, in addition to the direct effect of the higher input costs. Thus, countermerging is profitable with Cournot competition.

However, a slight modification of the basic model can replicate welfare-reducing vertical foreclosure as an equilibrium outcome. As in Hart and Tirole (1990), let us introduce a fixed cost of integration, $F$. We can consider $F$ as internal governance costs and/or legal costs associated with vertical integration (see the discussion in Hart and Tirole, 1990). Then, we can find a range of fixed costs for which the initial integration is profitable but a countermerger is not. The reason is that the magnitude of the profit increase can be bigger for the initial integration than for the countermerger. To see this, from Eqs. (18) and (22), we have

$$
4\left[\mathrm{G}^{\mathrm{n}}-\mathrm{G}^{\mathrm{cm}}\right]=(1+\rho)[\pi(\underline{c}, \bar{c})+\pi(\bar{c}, \underline{c})-2 \pi(\underline{c}, \underline{c})]+\rho[2 \bar{\phi}+\phi]
$$

In the Coumot oligopoly (see the Appendix), 


$$
4\left[G^{v: l}-G^{\mathrm{CM}}\right]=\frac{\Delta}{9}[(3 \Delta-2 \beta)+7 \beta \rho], \text { where } \beta=\mathrm{a}-\bar{c} \text { and } \Delta=\bar{c}-\underline{c} \text {. }
$$

Therefore, the gains from the initial merger $\left(\mathrm{G}^{\mathrm{v}:}\right)$ is larger than gains from the countermerger $\left(G^{\mathrm{CM}}\right)$ if $\rho>[2 \beta-3 \Delta] / 7 \beta$. If this inequality holds, we can find $F$ such that $\mathrm{G}^{\mathrm{V}: \mathrm{l}}>\mathrm{F}>\mathrm{G}^{\mathrm{CM}}$; the initial merger is profitable but the countermerger is not.

The condition above is more likely to be satisfied as the cost correlation parameter ( $\rho$ ) or the cost differential $(\Delta)$ increases. The reason for this comparative statics result can be explained in the following way. Let $\Pi_{U i-D i}^{k}$ be the combined profits of $U_{i}$ and Di with the vertical structure of $k$, where $k=N I$, PI, and FI. Then, $G^{\mathrm{VI}}=\Pi_{\mathrm{U} \cdot \mathrm{DI}}^{\mathrm{PI}}-\Pi_{\mathrm{Ui} \cdot \mathrm{DI}}^{\mathrm{NI}}$ and $\mathrm{G}^{\mathrm{CM}}$ $=\Pi_{\mathrm{U} 2-\mathrm{D} 2}^{\mathrm{TI}}-\Pi_{\mathrm{U} 2-\mathrm{D} 2}^{\mathrm{PI}}$. Both U1-D1 and U2-D2 have the same level of combined profits under $\mathrm{NI}$ and FI due to the symmetric vertical structure. Hence, we have $\mathrm{G}^{\mathrm{v}: \mathrm{l}}>\mathrm{G}^{\mathrm{cM}}$ if $\Pi^{\mathrm{Pl}}>$ $\left[\Pi^{\mathrm{NI}}+\Pi^{\mathrm{FI}}\right] / 2$, where $\Pi^{\mathrm{k}}=\Pi_{\mathrm{U} 1-\mathrm{DI}}^{\mathrm{k}}+\Pi_{\mathrm{U} 2-\mathrm{D} 2}^{\mathrm{k}}$ is industry profit under vertical structure $k$; industry profit under PI is higher than the average industry profits under NI and FI. Note that as $\rho$ increases, industry profits under both NI and FI decrease but stay unchanged under PI, which makes $\mathrm{G}^{\mathrm{V}: \mathrm{I}}>\mathrm{G}^{\mathrm{CM}}$ more likely. In addition, under Cournot oligopoly, the loss in industry profits from increased cost correlation is given by $[\pi(\underline{c}, \bar{c})+\pi(\bar{c}, \underline{c})]$ $[\pi(\underline{c}, \underline{c})+\pi(\bar{c}, \bar{c})]=4 \Delta^{2} / 9$, thus is proportional to $\Delta^{2}$.

It can be also verified that introducing a fixed cost of integration can deter a countermerger without causing hold-out problems in Cournot oligopoly. With the fixed cost of vertical merger, the equilibrium bidding price for $U 1$ is given by $b=\Pi_{U l-D 1}^{P I}-\Pi_{D 2}^{P I}$ F. For $\mathrm{U} 1$ not to have the incentive to hold-out, it is required that $b>\Pi_{U 2}^{\mathrm{PI}}$, i.e., $\Pi_{\mathrm{Ul} \cdot \mathrm{Dl}}^{\mathrm{PI}}$ $\Pi_{U 2-D_{2}}^{\mathrm{PI}}>\mathrm{F}$. Also note that $\Pi_{\mathrm{U} 1-\mathrm{D}_{1}}^{\mathrm{PI}}>\Pi_{\mathrm{U} 2-\mathrm{D} 2}^{\mathrm{FI}}$, that is, a countermerger reduces the profits of the initially merged firm, which implies that $\Pi_{\mathrm{U} 1 \cdot \mathrm{DI}_{1}}^{\mathrm{PI}}-\Pi_{\mathrm{U} 2 \cdot \mathrm{D} 2}^{\mathrm{PI}}>\mathrm{G}^{\mathrm{CM}}=\Pi_{\mathrm{U} 2 \cdot \mathrm{D} 2}^{\mathrm{F}}-\Pi_{\mathrm{U} 2-\mathrm{D} 2}^{\mathrm{PI}}$. Therefore, we can always find a range of $F$ which prevents countermerging without causing the hold-out problem $\left(\Pi_{\mathrm{Ul}-\mathrm{DI}}^{\mathrm{PI}}-\Pi_{\mathrm{U} 2-\mathrm{D} 2}^{\mathrm{PI}}>\mathrm{F}>\mathrm{G}^{\mathrm{CM}}\right)$.

Furthermore, with Cournot oligopoly, we can show that both consumer surplus and social welfare are unambiguously reduced with a vertical merger. Consumer surplus 
is given by $\frac{1}{2} Q^{2}$, where $Q$ is the total industry output. Under $N I, Q=\frac{2}{3}(\beta+\Delta)$ when both upstream firms have the cost realization of $\underline{c}$ while $Q=\frac{2}{3} \beta$ in all other cases. Under

NI, therefore, consumer welfare is given by:

$$
\operatorname{CS}^{\mathrm{N}}=\frac{1+\rho}{4} \frac{1}{2}\left[\frac{2}{3}(\beta+\Delta)\right]^{2}+\left(1-\frac{1+\rho}{4}\right) \frac{1}{2}\left[\frac{2}{3} \beta\right]^{2}
$$

Under PI, D2's marginal cost is always $\bar{c}$. Hence, $Q=q(\underline{c}, \bar{c})+q(\bar{c}, \underline{c})=\frac{2 \beta+\Delta}{3}$ when U1 has $\underline{c}$ while $Q=\frac{2}{3} \beta$ when $\mathrm{U} 1$ has $\bar{c}$.

$$
\operatorname{CS}^{\mathrm{\mu}}=\frac{1}{2} \frac{1}{2}\left[\frac{2 \beta+\Delta}{3}\right]^{2}+\frac{1}{2} \frac{1}{2}\left[\frac{2}{3} \beta\right]^{2}
$$

Thus, consumers are worse-off with vertical merger since

$$
\left[\mathrm{CS}^{\mathrm{N}}-\mathrm{CS}^{\mathrm{p}}\right]=\frac{\Delta}{36}[\Delta+\rho(2 \Delta+4 \beta)]>0 .
$$

Let us define social welfare as the sum of industry profits and consumer welfare: $W=$ CS $^{\mathbf{k}}$. With a fixed cost of integration $F$, it can be verified that

$$
\left[W^{\mathrm{N}}-\mathrm{W}^{\mathrm{P}}\right]=\frac{\Delta}{36}[(3 \beta-4 \Delta)-4 \rho(\beta-\Delta)]-F
$$

Recall that for an equilibrium vertical merger to occur $F>G^{C M}=\frac{\Delta}{36}[(2 \beta+4 \Delta)-\rho(3 \beta+$ $\Delta)$ ]. Hence,

$$
\left[W^{\mathrm{NI}}-W^{\mu}\right]>\frac{\Delta}{36}[(5-7 \rho) \beta+3 \rho \Delta)>0 \text { since we assume } \rho \leq 1 / 2 \text {. }
$$

\section{Concluding Remarks}

In this paper, we analyzed a model of vertical foreclosure in which the choice of input specificity is endogenously derived. In the model, vertical foreclosure occurs as the upstream division of the integrated firm makes a specialized input for its sister downstream division. The choice of a specialized input serves as a natural commitment mechanism for the integrated firm not to supply the rival downstream firms because the input is less useful to other downstream firms. Thus, our consideration of different 
specifications of inputs enabled us to dispense with the controversial price commitment assumption in O-S-S.

For vertical integration to generate an anti-competitive foreclosure in our model, it is required that the upstream division of the integrated firm has incentives to provide a specialized input though it would provide the generalized input as an independent firm. The changes in incentives regarding the choice of input specification can be explained by the externalities that the choice of a specialized input entails; vertical integration allows the upstream firm to internalize the benefit to its sister downstream division of raising her rival firm's costs. We also considered the possibility of a counter-merger by the foreclosed downstream firm and the potential hold-out problem by the target upstream firm in the acquisition process. These considerations yielded a coherent model of vertical integration in which conditions for an anti-competitive vertical foreclosure are explicitly derived. In addition, we demonstrated the possibility of an anti-competitive vertical foreclosure with closed-form solutions for a particular oligopoly model of spatial competition.

We conclude by discussing possible extensions of the model. In this paper, we focused on the case of a symmetric equilibrium in input specifications in the absence of vertical mergers by limiting our attention to the case of $\rho \leq 1 / 2$. When $\rho>1 / 2$, we can have asymmetric equilibria in which one firm chooses a specialized input while the other chooses a generalized input. In this case, it would be interesting to see how this initial asymmetry affects the incentives to vertically integrate.

One way to interpret our model is to consider the low cost event as an innovation. Then, the choice of input specification is equivalent to a decision of R\&D resource allocation between projects with fixed $R \& D$ resources. One promising avenue of future research is to endogenize the $R \& D$ incentives and to see how vertical integration affects R\&D incentives and how this effect influences the vertical integration decision. ${ }^{19}$

\footnotetext{
${ }^{19} \mathrm{Choi}$ and $\mathrm{Yi}(1996)$ analyze vertical integration as a way to relax R\&D competition. See also Baldwin (1983).
} 


\section{Appendix}

\section{The Non-emptiness of the Set $\Sigma$ :}

\section{The Case of Cournot Competition with Linear Demand Curve $P=a-O$}

Straightforward calculations yield the following standard results:

$$
\begin{aligned}
& \mathrm{q}(\bar{c}, \bar{c})=\frac{a-\bar{c}}{3}, \pi(\bar{c}, \bar{c})=\left(\frac{a-\bar{c}}{3}\right)^{2} \\
& \mathrm{q}(\underline{c}, \underline{c})=\frac{a-\underline{c}}{3}, \pi(\underline{c}, \underline{c})=\left(\frac{a-\underline{c}}{3}\right)^{2} \\
& \mathrm{q}(\bar{c}, \underline{c})=\frac{a-2 \bar{c}+\underline{c}}{3}, \pi(\bar{c}, \underline{c})=\left(\frac{a-2 \bar{c}+\underline{c}}{3}\right)^{2} \\
& \mathrm{q}(\underline{c}, \bar{c})=\frac{a-2 \underline{c}+\bar{c}}{3}, \pi(\underline{c}, \bar{c})=\left(\frac{a-2 \underline{c}+\bar{c}}{3}\right)^{2} \\
& \bar{\phi}=\frac{a-\bar{c}}{3} \Delta \\
& \underline{\phi}=\frac{a-2 \bar{c}+\underline{c}}{3} \Delta, \text { where } \Delta=\bar{c}-\underline{c}
\end{aligned}
$$

By substituting these expressions into Eq. (17) in the text, we have

$$
\rho^{*}=\frac{\underline{\phi}-[\pi(\underline{c}, \bar{c})-\pi(\mathcal{c}, \underline{c})]}{\underline{\phi}+[\pi(\underline{c}, \bar{c})-\pi(\underline{c}, \underline{c})]}=\frac{a-7 \Delta}{5 a-5 \Delta}
$$

Therefore, $\rho^{*} \leq 1 / 5$ and is decreasing in $\Delta$. Furthermore, $\rho^{*} \leq 0$ if $\Delta \geq 2 / 7$.

\section{The Case of Hotelling Competition}

In this case, we have

$$
\begin{aligned}
& \pi(\bar{c}, \bar{c})=\pi(\underline{c}, \underline{c})=\frac{t}{2} \\
& \pi(\bar{c}, \underline{c})=\frac{t}{2}-\frac{\Delta}{3}+\frac{\Delta^{2}}{18 t} \\
& \pi(\underline{c}, \bar{c})=\frac{t}{2}+\frac{\Delta}{3}+\frac{\Delta^{2}}{18 t} \\
& \bar{\phi}=\frac{\Delta}{2}
\end{aligned}
$$




$$
\phi=\frac{\Delta}{2}-\frac{\Delta^{2}}{6 t}
$$

Therefore, we have

$$
\rho^{*}=\frac{\phi-[\pi(c, \bar{c})-\pi(c, c)]}{\underline{\phi}+[\pi(c, \bar{c})-\pi(\underline{c}, \underline{c})]}=\frac{3-4 \frac{\Delta}{t}}{15-2 \frac{\Delta}{t}}
$$

As in the Cournot case, $\rho^{*} \leq 1 / 5$ and decreases as $\Delta$ increases. Furthermore, $\rho^{*}$ decreases as $t$ decreases, and $\rho^{*} \leq 0$ if $\Delta t \geq 3 / 4$. 


\section{References}

Aghion, Philippe and Bolton, Patrick, "Contracts as a Barrier to Entry," American Economic Review, June 1987, 77, 388-401.

Baba, Yasunori, Takai, Shinji, and Mizuta, Yuji, "The Japanese Software Industry: the 'Hub Structure' Approach," Research Policy, 1995, 24, pp. 473-86.

Baldwin, Carliss Y. "Innovation and the Vertical Structure of Industry," Harvard Business School Working Paper Number 84-16, 1983.

Bolton, Patrick and Whinston, Michael D. "Incomplete Contracts, Vertical Integration, and Supply Assurance," Review of Economic Studies, January 1993, 60 121-48.

Bonanno, Giacomo and Vickers, John. "Vertical Separation," Journal of Inctustrial Economics, March 1988, 36, 257-66.

Bork, Robert H. The Antitrust Paradox: A Policy at War with Itself, New York, Basic Books, 1978.

Brock, Gerald, "Dominant Firm Response to Competitive Challenge: Peripheral Manufacturers' Suit Against IBM (1979-1983)," in J. E. Kowka and L. J. White, eds., The Antitrust Revolution, New York: Harper Collins, 1989.

Bulow, Jeremy I., Geanakoplos, John D., and Klemperer, Paul D. "Multimarket Oligopoly: Strategic Substitutes and Complements," Journal of Political Economy, June 1985, 93, 488-511.

Carlton, Dennis. "Vertical Integration in Competitive Markets under Uncertainty," Journal of Industrial Economics, 1979, 27, 189-209.

Choi, Jay Pil, "Preemptive R\&D, Rent Dissipation, and the 'Leverage Theory'," Quarterly Journal of Economics, November 1996, pp. 1153-82.

Choi, Jay Pil and Yi, Sang-Seung. "Equilibrium Vertical Foreclosure with Investment," unpublished manuscript, November 1996.

Church, Jeffrey and Gandal, Neil, "Systems Competition, Vertical Merger and Foreclosure," unpublished manuscript, November 1995.

Dasgupta, Partha and Maskin, Eric, "The Simple Economics of Research Portfolios," Economic Journal, 1987, 97, 587-95.

Gleick, James, “The Microsoft Monopoly," The New York Times Magazine, November 5, 1995 / Section 6. 
Hart, Oliver and Tirole, Jean. "Vertical Integration and Market Foreclosure," Brookings Papers on Economic Activity, Microeconomics, 1990, 205-76.

Klass, Michael W. and Salinger, Michael A. "Do New Theories of Vertical Foreclosure Provide Sound Guidance for Consent Agreements in Vertical Merger Cases?," Antitrust Bulletin, 1995, 40, 667-98.

Klein, Benjamin, Crawford, Robert G., and Alchian Armen A., "Vertical Integration, Appropriable Rents, and the Competitive Contracting Process," Journal of Law and Economics, 1978, 21, 297-326.

McAfee, R. Preston and Schwartz, Marius. "Opportunism in Multilateral Vertical Contracting: Nondiscrimination, Exclusivity, and Uniformity," American Economic Review, 1994, 84, 210-30.

McLaren, John. “'Globalization' and Vertical Structure," unpublished manuscript, July 1996.

Merton, Robert K., "Singletons and Multiples in Scientific Discovery," Proceedings of the American Philosophical Society, 1961, 105 (5), pp. 470-86.

Ordover, Janusz A., Saloner, Garth and Salop, Steven C. "Equilibrium Vertical Foreclosure," American Economic Review, March 1990, 80, 127-42.

."Equilibrium Vertical Foreclosure: Reply," American Economic Review, June 1992, 82, 698-703.

Porter, Michael E. and Spence, A. Michael. "Vertical Integration and Differentiated Inputs," Harvard Institute of Economic Research Discussion Paper No. 576, 1977.

Rasmusen, Eric B., Ramsey, J. Mark, and Wiley, Jr., John S., "Naked Exclusion," American Economic Review, December 1991, 81, 1137-1145.

Reiffen, David. "Equilibrium Vertical Foreclosure: Comment," American Economic Review, June 1992, 82, 694-97.

Reiffen, David and Vita, Michael, "Comment: Is There New Thinking on Vertical Mergers?" Antitrust Law Journal, 1995, 63, 917-41.

Riordan, Michael H. "Anticompetitive Vertical Integration by a Dominant Firm," unpublished manuscript, March 1996.

Salinger, Michael. "Vertical Mergers and Market Foreclosure," Quarterly Journal of Economics, 1988, 103, 345-56 
Salop, Steven C. and Scheffiman, David T. "Raising Rivals' Costs," American Economic Review, May 1983, 73, 267-71.

Spengler, Joseph J. "Vertical Integration and Antitrust Policy," Journal of Political Economy, 1950, 58, 347-52.

Tirole, Jean. The Theory of Industrial Organization, The MIT Press: Cambridge, 1988.

Whinston, Michael D., "Tying, Foreclosure, and Exclusion," American Economic Review, September 1990, 80, 837-59. 


\section{6-1997 Discussion Paper Series}

Department of Economics

Columbia University

1022 International Affairs Bldg.

420 West 118th Street

New York, N.Y., 10027

The following papers are published in the 1996-97 Columbia University Discussion Paper series which runs from early November to October 31 of the following year (Academic Year).

Website: http://www.columbia.edu/dlc/wp/econ/index.html.

You may download any papers found on this site.

For Ordering Hardcopies:

Domestic orders for discussion papers are available for purchase at the cost of $\$ 8.00$ (U.S.) Per paper and $\$ 140.00$ (US) for the series.

Foreign orders cost $\$ 10.00$ (US) per paper and $\$ 185.00$ for the series.

To order discussion papers, please write to the Discussion Paper Coordinator at the above address along with a check for the appropriate amount, made payable to Department of Economics, Columbia University. Please be sure to include the series number of the requested paper when you place an order. 
9697-01 Fertility Behavior Under Income Uncertainty

9697-02 Trade Restrictions, imperfect Competition and National Welfare with Foreign Capital Inflows

9697-03 Restructuring an Industry during Transition: a Two-Priced Model

9697-04 A Conformity Test for Cointegration

9697-05 Low-Wage Employment Subsidies in a Labor-Turnover Model of the 'Natural Rate' (November 1996)

9697-06 The Knowledge Revolution

9697-07 The Role of Absolute Continuity in "Merging Opinions" and "Rational Learning"

9697-08 The Soviet Bloc and the Soviet Union: Why did they fall apart?

9697-09 Regionalism and Multilateral Tariff Cooperation

9697-10 Supplier Relations and the Market Context: A theory of handshakes

9697-11 Vertical Foreclosure with the Choice of Input Specifications

9697-12 Equilibrium Vertical Foreclosure with Investment by: P. Ranjan

by: P. Ranjan

by: R. Ericson

by: P. Dhrymes

by: H.T. Hoon

E. Phelps

by: G. Chichilnisky

by: R. Miller

C.W. Sanchirico

by: P. Desai

by: K. Bagwell

R. Staiger

by: J. McLaren

by: J.P. Choi

S. Yi

by: J.P. Choi

S. $\quad \mathrm{Yi}$ 